\title{
Program Berkelanjutan Membantu Nagari Membangun di Nagari Sungai Kamuyang Kabupaten Lima Puluh Kota
}

\author{
Dwi Yuzaria', Rusda Khairati², Adisti Rastosari'1, A. Irzal Rias' ${ }^{3}$, dan Daz Edwiza ${ }^{4}$ \\ 1Fakultas Peternakan, Universitas Andalas, Kampus Limau Manis, Padang, 25163. Indonesia \\ 2Fakultas Pertanian, Universitas Andalas, Kampus Limau Manis, Padang, 25163. Indonesia \\ ${ }^{3}$ Fakultas Hukum, Universitas Andalas, Kampus Limau Manis, Padang, 25163. Indonesia \\ ${ }^{4}$ Fakultas Teknik, Universitas Andalas, Kampus Limau Manis, Padang, 25163. Indonesia \\ E-mail: dyuzaria@ansci.unand.ac.id
}

Keywords: BUMNag, capacity, contribution, Nagari Sungai Kamuyang

Kata Kunci:

Bumnag,

kontribusi,

kapasitas, Nagari Sungai Kamuyang

\begin{abstract}
The assisting Village development program is an activity carried out by the Andalas University Community Service Organization to Help Nagari improve the community economy in nagari Sungai Kamuyang, Luak District, Lima Puluh Kota Regency. It was implemented to help the Sungai Kamuyang village solve problems that hinder Nagari development. The problem faced by Nagari Sungai Kamuyang is that the utilization of natural and other resources is not optimal so that the poverty rate in this village is still quite high. Meanwhile, BUMNag which has been operating since 2017 have not been able to contribute to the original income of the village and foster economic activities for poverty alleviation. The general objective of this activity is to increase the capacity of BUMNag Sungai Kamuyang in developing its business to support the achievement of an independent Nagari, while the specific objective will be to map out the overall management problems of BUMNag Sungai Kamuyang, identify potential and strategic business units that can be implemented, compile business plans. To these potential and strategic business units and conduct business training and mentoring (training and mentoring) for the Sungai Kamuyang BUMNag Management Team in order to strengthen their capacity as a professional business entity. The solution offered is to carry out activities to increase the capacity of BUMNag businesses so that BUMNag become village business entities that are able to contribute to the village government.
\end{abstract}

\begin{abstract}
ABSTRAK
Program Pengabdian kepada Masyarakat ini dilaksanakan untuk membantu nagari Sungai Kamuyang menyelesaikan masalah-masalah yang menghambat pembangunan Nagari. Permasalahan yang dihadapi Nagari Sungai Kamuyang adalah belum optimalnya pemanfaatan sumber daya alam dan lainnya sehingga masih cukup tingginya angka kemiskinan di nagari ini. Sementara BUMNag yang sudah beroperasi sejak 2017 yang lalu belum mampu memberikan kontribusi terhadap pendapatan asli nagari dan menumbuhkan kegiatan ekonomi bagi pengentasan kemiskinan. Tujuan Umum kegiatan ini adalah meningkatkan kapasitas BUMNag Sungai Kamuyang dalam mengembangkan usahanya untuk menunjang capaian nagari mandiri, sementara tujuan khusus akan dilakukan pemetaan permasalahan manajemen secara menyeluruh terhadap BUMNag Sungai Kamuyang, mengidentifikasi unit-unit bisnis yang potensial dan strategis serta dapat diimplementasikan, menyusun rencana bisnis terhadap unit-unit bisnis potensial dan strategis tersebut dan melakukan training dan mentoring (pelatihan dan pendampingan) bisnis bagi Tim Manajemen BUMNag Sungai Kamuyang dalam rangka penguatan kapasitas sebagai badan usaha yang profesional. Solusi yang ditawarkan adalah dengan melakukan kegiatan peningkatan kapasitas bisnis BUMNag hingga mampu memberikan kontribusi kepada pemerintahan nagari.
\end{abstract}




\section{PENDAHULUAN}

Nagari Sungai Kamuyang yang menjadi sasaran program ini dipilih dengan pertimbangan bahwa nagari ini merupakan daerah rural-urban yang terletak di batas Kota Payakumbuh dan Kabupaten Lima Puluh Kota, memiliki sumberdaya alam yang potensial, namun jumlah penduduk miskinnya cukup besar (yakni 17,58\%), dan sebagian besar masyarakat masih mengandalkan sektor pertanian menjadi mata pencaharian utama mereka. Salah satu masalah mendasar yang dihadapi nagari saat ini adalah relatif rendahnya kualitas sumber daya manusia (SDM) di desa, termasuk aparatur nagari yang memegang kekuasaan administrasi pemerintahan dan pengelolaan dana nagari. Rendahnya kualitas pemahaman dan penguasaan aparatur nagari terhadap tata kelola administrasi pemerintahan nagari yang tertib dan tata kelola keuangan nagari yang transparan dan akuntabel, menimbulkan kekhawatiran salah kelola dana desa yang berujung pada munculnya masalah hukum di kemudian hari. Menurut Febriana dan Made (2015) bahwa SDM merupakan faktor sentral dalam suatu organisasi, yang menentukan pencapaian target yang ditetapkan, sementara menurut Kuryanto dan Syarifuddin (2008) perusahaan yang mampu mengelola sumberdaya manusianya dan pengetahuannya dengan baik maka perusahaan itu akan memiliki keunggulan kompetitif yang menunjang kinerja perusahaan.

Pengembangan kapasitas (capacity building) para aparatur desa sangat dibutuhkan agar pengelolaan dana desa yang tepat sasaran dan efektif dalam perencanaan serta pembangunan desa. Leba (2015) menjelaskan tentang kapasitas desa, terutama pemerintah desa, bukan sekadar kesanggupan dan kelancaran pemerintah desa menjalankan tugas pokok dan fungsinya atau mengikuti prosedur administrasi yang sudah baku. Kapasitas dalam konteks ini adalah penguasaan pengetahuan dan informasi maupun keterampilan menerapkan instrumen kebijakan dan program untuk menjalankan fungsi-fungsinya secara efektif dan efisien. Tiga tingkat kemampuan yang harus dimiliki oleh perangkat desa (Asrori, 2014) yaitu: 1) kemampuan dasar; 2) kemampuan manajemen; 3) kemampuan teknis. Kemampuan dasar meliputi pengetahuan tentang regulasi desa, pengetahuan tentang dasar-dasar pemerintahan des, dan pengetahuan tentang tugas pokok dan fungsi. Kemampuan manajemen meliputi manajemen SDM, pelayanan publik, aset, dan manajemen keuangan. Sedangkan kemampuan teknis meliputi penyusunan administrasi desa, perencanaan pembangunan, anggaran, penyusunan perdes, dan pelayanan publik. Yang lebih penting lagi, kapasitas merupakan prakarsa untuk melakukan inovasi atau pembaharuan terhadap pengelolaan pembangunan, pemerintahan dan kemasyarakatan agar desa berkembang lebih dinamis dan maju mencapai visi-misi yang digariskan.

Menurut African Capacity Building Foundation (ACBF, 2001) peningkatan kapasitas adalah sebuah proses untuk meningkatkan kemampuan menganalisa lingkungannya; mengidentifikasi masalah-masalah, kebutuhan-kebutuhan, isu-isu, dan peluang-peluang; memformulasi strategistrategi untuk mengatasi masalah-masalah tersebut. Sedang menurut Milen (2004) adalah sebuah proses peningkatan secara terus menerus (berkelanjutan) dari setiap individu, organisasi atau institusi, dan tidak hanya terjadi satu kali. Pengembangan kapasitas merupakan proses internal yang hanya bisa difungsikan dan dipercepat dengan bantuan dari luar.

Tujuan Umum dari kegiatan pengabdian ini adalah untuk meningkatkan kapasitas BUMNag Sungai Kamuyang dalam mengembangkan usahanya untuk menunjang capaian nagari mandiri. Sementara tujuan khususnya adalah; 1) Melakukan pemetaan permasalahan manajemen secara menyeluruh terhadap BUMNag Sungai Kamuyang; 2) Mengidentifikasi unit-unit bisnis yang potensial dan strategis serta dapat diimplementasikan; 3) Menyepakati solusi-solusi yang akan dilakukan untuk menyelesaikan permasalahan-permasalahan yang dihadapi BUMNag Sungai Kamuyang; dan 4) Menyusun rencana kegiatan atas solusi-solusi yang telah disepakati, 
melakukan pelatihan dan pendampingan bisnis bagi Tim Manajemen BUMNag Sungai Kamuyang dalam rangka penguatan kapasitas sebagai badan usaha yang profesional.

Identifikasi permasalahan, solusi dan rencana kegiatan yang akan dilaksanakan yang dibahas dalam FGD ini seluruhnya berhubungan dengan BUMNag Sungai Kamuyang yang saat ini berjalan tidak lancar. Unit-unit bisnis BUMNag Sungai Kamuyang yang teridentifikasi bermasalah antara lain :

a. Keuangan Syariah; mengelola usaha kredit mikro nagari dan bank mini

b. Penyewaan; mengelola usaha penyewaan papan bunga dan peralatan memasak

c. Pariwisata; mengelola usaha pemandian batang tabik dan agrowisata

d. Barang dan Jasa; mengelola usaha pengadaan sembako, konveksi dan travel

e. Ranah Bundo; penyewaan peralatan catering

Untuk mengetahui problem utama yang dihadapi oleh BUMNag Nagari Sungai Kamuyang perlu diidentifikasi secara menyeluruh dan transparan permasalahan apa saja yang dihadapi oleh unit-unit bisnis pada BUMNag tersebut. Manfaat dan dampak yang diharapkan adalah terjadinya perubahan, peningkatan, pengembangan atau nilai tambah dan kapasitas yang signifikan dalam bisnis yang dikelola oleh BUMNag Sungai Kamuyang.

\section{METODE}

Identifikasi permasalahan yang dihadapi unit-unit bisnis BUMNag Sungai Kamuyang dilakukan dengan metoda Focus Group Discussion (FGD). Dalam metode FGD ini pengabdi lebih berperan sebagai fasilitator atau moderator dan melakukan monitoring serta mencatat interaksi antar peserta (Punch, 2014). Penggunaan metode FGD dalam kegiatan ini dilakukan untuk menjaring informasi mengenai kondisi riil kapasitas desa dan potensi yang dimiliki untuk dikelola. FGD dilaksanakan dengan mengundang berbagai pihak yang berkompeten dan berhubungan langsung dengan kegiatan BUMNag Sungai Kamuyang seperti Camat Luak, Wali Nagari Sungai Kamuyang, Sekretaris Nagari, perangkat-perangkat pemerintahan Nagari, Badan Musyawarah Nagari, ketua unit-unit bisnis BUMNag, Kepala Jorong, Tokoh Masyarakat, dan Stakeholder BUMNag Sungai Kamuyang lainnya. FGD ini telah dilaksanakan pada tanggal 12 Desember 2020, bertempat di Balai Adat Kenagarian Sungai Kamuyang Kecamatan Luak, Kabupaten Lima Puluh Kota.

\section{HASIL DAN PEMBAHASAN}

\section{Profil Nagari Sungai Kamuyang}

Profil Nagari Sungai Kamuyang secara geografis terletak di Kecamatan Luak, Kabupaten Limapuluh Kota, Provinsi Sumatra Barat, dengan luas 3.037 hektar. Nagari ini berjarak sekitar 3 kilometer dari ibu kota kecamatan, 16 kilometer dari ibu kota kabupaten, Sarilamak. Nagari Sungai Kamuyang terdiri dari 9 jorong, yakni Subaladung, Tabiang, Tanjuang Kaliang, Batang Tabik, VI Kampuang, VIII Kampuang, XII Kampuang, Rageh, Madang Kadok. Nagari Sungai Kamuyang terletak pada ketinggian 300 - 1.000 meter di atas permukaan laut dengan topografi yang bervariasi, mulai dari miring, ketinggian dan morfologi daratan, wilayah pegunungan, dataran tinggi dan dataran rendah. Nagari ini terletak pada daerah relatif yang bergelombang dan berbukit yang memiliki kemiringan tanah yang berkisar antara 5 - 40\% bahkan ada yang lebih dari 40\%. Jenis tanah di Nagari Sungai Kamuyang pada umumnya berupa tanah latosol coklat dan padzolik merah kuning, PH tanahnya agak masam sampai sedang yang bersifat tahan terhadap erosi dan cocok untuk pertanian. Tata air Nagari Sungai Kamuyang terdiri dari air 
permukaan dan air bawah tanah, dan merupakan sumber mata air terbanyak di Kecamatan Luak, salah satunya Pemandian Alam di Batang Tabik. Penggunaan lahan di Nagari Sungai Kamuyang sangat dipengaruhi oleh kondisi topografi, iklim, jenis tanah, dan tata air kawasan ini yang akhirnya juga berpengaruh terhadap kehidupan sosial ekonomi masyarakat. Lahan di nagari ini penggunaanya didominasi oleh peruntukan pertanian (persawahan, kolam ikan dan perkebunan), hutan, pemukiman, sarana prasarana/infrastruktur, dan bentuk lainnya.

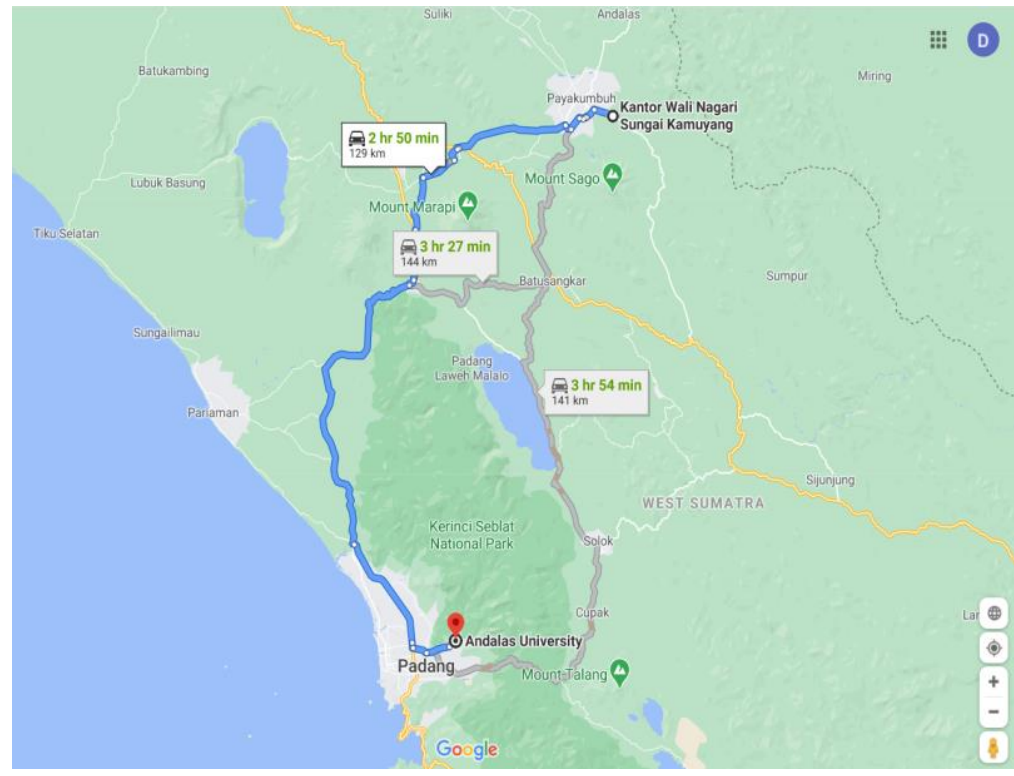

Gambar 1. Peta Lokasi Mitra Binaan Nagari Sungai Kamuyang

\section{Potensi Pengembangan Wilayah}

Sektor pertanian, khususnya bercocok tanam padi dan palawija, merupakan mata pencaharian utama masyarakat Nagari Sungai Kamuyang. Sektor ini merupakan sektor andalan karena didukung oleh ketersedian lahan, kondisi alam, iklim, curah hujan, ketersedian air dan struktur tanah yang sangat mempengaruhi hasil produksi terutama padi dan palawija. Tanaman sayur-sayuran (hortikultura) juga termasuk komoditi yang memiliki potensi penembangan yang sangat baik bagi nagari ini, karena didukung oleh kesesuaian lahan yang sesuai dengan budidaya hortikultura, sumber daya manusia dan akses pasar yang relatif dekat, yakni pasar Payakumbuh. Untuk menunjang pengembangan hortikulutra di nagari ini telah terbentuk 3 Gapoktan (Gabungan Kelompok Tani) di bidang sayur organik, padi/beras organik, dan pupuk organik. Selain pertanian tanaman pangan, potensi sumber daya alam lainnya berupa lahan perkebunan. Beberapa tanaman perkebunan rakyat di antaranya coklat (kakao), kelapa, tembakau, cengkeh, kulit manis dan lain-lain sudah dibudidayakan di setiap jorong. Tanaman tembakau dibudidayakan oleh masyarakat terutama di Jorong Madang Kadok, Jorong Subaladung dan sebagian Jorong Rageh. Potensi ini sangat bagus untuk dikembangkan karena didukung lahan (tanahulayat) yang luas sekitar 150 hektar. Jika dioptimalkan potensi ini diharapkan bisa mengarah kepada perkebunan yang intensif.

Usaha peternakan yang berkembang di Nagari Sungai Kamuyang saat ini adalah usaha peternakan sapi dan unggas. Berdasarkan kondisi lahan dan kekayaan alam Nagari Sungai Kamuyang, yang terkenal akan sumber airnya yang besar, jernih dan stabil dalam kondisi iklim yang ekstrim sekalipun, lokasi yang sangat memadai bagi perikanan air tawar. Usaha budidaya perikanan merupakan suatu usaha yang sangat cocok dikembangkan di sebagian wilayah Nagari Sungai Kamuyang untuk meningkatkan perekonomian masyarakat. 
Objek wisata, disamping usaha pertanian dan peternakan potensi wisata Nagari Sungai Kamuyang juga layak dikembangkan. Objek wisata yang terdapat di Nagari Sungai Kamuyang yang sudah ada saat ini pemandian Batang Tabik. Objek Wisata ini sudah lama dikembangkan oleh Pemerintah Kabupaten dan merupakan tempat pemandian alam yang sangat terkenal bagi masyarakat Payakumbuh dan Kabupaten Lima Puluh Kota. Selain pemandian Batang Tabik, objek lainnya adalah Panorama Kubua Jawi, yang terletak di pinggang gunung Sago dengan ketinggian $1.100 \mathrm{mdpl}$. Lokasi ini ramai dikunjungi pada sore sampai malam hari untuk menikmati Sun set di sore hari dan gemerlapnya suasana kota Payakumbuh dimalam hari dengan udara yang dingin. Sudah ada beberapa rumah kopi dan rumah susu yang melayani kebutuhan makanan dan minuman untuk wisatawan menikmati suasana pegunungan, namun masih dalam kondisi yang sangat sederhana. Saat ini objek wisata Kubua Jawi belum tertata dengan baik, padahal potensi ekowisatanya sangat besar untuk meningkatkan perekonomian masyarakat. Sarana dan prasarananya harus dikembangkan dengan membangun agrowisata hortikultura dan agrowisata sapi perah dengan menyediakan lokasi belanja sayur dan buah, serta belanja produk-produk susu dari pengolahan susu hasil produksi peternak sapi perah di lokasi ini.
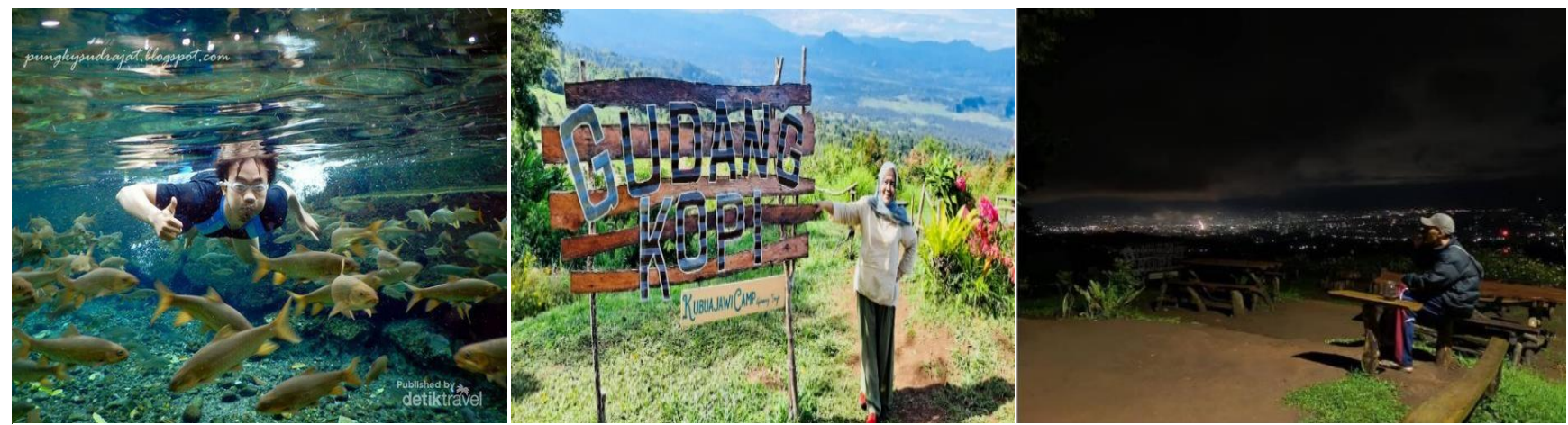

Gambar 2. Objek Wisata yang Memiliki Potensi di Nagari Kamuyang; Pemandian Batang Tabik, Panorama Gudang Kopi, dan Panorama Kubua Jawi.

\section{Badan Usaha Milik Nagari Sungai Kamuyang}

BUMNag merupakan Lembaga usaha yang dimiliki nagari Sungai Kamuyang. Sudah beroperasi sejak tahun 2017. Berdiri berdasarkan SK Wali Nagari Sungai Kamuyang No. 48 tahun 2016 tentang Badan Usaha Milik Nagari Sungai Kamuyang. Sebagai suatu lembaga ekonomi modal usahanya dibangun atas inisiatif masyarakat dan menganut asas mandiri. Meskipun demikian, tidak menutup kemungkinan BUMNag dapat mengajukan pinjaman modal kepada pihak luar, seperti dari pemerintah nagari atau pihak lain bahkan melalui pihak ketiga. Pendirian BUMNag didasarkan pada kebutuhan dan potensi nagari, sebagai upaya peningkatan kesejahteraan masyarakat. Pengelolaan BUMNag harus dilakukan secara profesional dan mandiri. BUMNag merupakan pilar kegiatan ekonomi di nagari yang berfungsi sebagai lembaga sosial (social institution) dan komersial (commercial institution). BUMNag sebagai lembaga sosial berpihak kepada kepentingan masyarakat melalui kontribusinya dalam penyediaan pelayanan sosial melalui peningkatan Pendapatan Asli Nagari. BUMNag Sungai Kamuyang sudah beroperasi sejak 3 tahun yang lalu telah mengembangkan berbagai kegiatan usaha di Nagari Sungai Kamuyang. Usaha yang telah dilakukan BUMNag ini adalah mengelola dana di antaranya:

a. Dana eks kredit mikro nagari

b. Penyertaan modal nagari

c. Hibah Kementerian Desa dan PDTT 
Dana tersebut digunakan untuk membiayai unit usaha di antaranya:

a. Jual beli syariah

b. Bank mini dan payment

c. Barang dan Jasa Pariwisata

\section{Desain dan Rencana Program}

Program ini didesain sebagai program yang terintegrasi dari suatu proses pelatihan dan pendampingan bisnis (training and mentoring) yang diawali dengan pemetaan permasalahan bisnis BUMNag Sungai Kamuyang, kajian kebutuhan pelatihan dan pendampingan (need assessment/gap analysis) bisnis berdasarkan kondisi bisnis eksisting usaha BUMNag yang menjadi mitra program ini. Pemetaan dan gap analysis dimaksud mencakup aspek-aspek bisnis setidaknya aspek manajemen bisnis, pemasaran, proses produksi, aspek lingkungan dan pembiayaan. Hasil pemetaan dan gap analisis akan dijadikan acuan utama program penguatan kapasitas yang akan dilaksanakan selama masa program diimplementasikan.

Tujuan Program:

a) Meningkatkan kemampuan berwirausaha bagi Tim Manajemen

b) Meningkatkan kapasitas Tim Manajemen memasuki dunia usaha yang memanfaatkan potensi lokal

Konsep Program:

a) Program pelatihan yang diberikan merupakan dalam bentuk pelatihan yang bersifat terapan. Metode pengajaran mencakup 40\% teori dan 60\% praktek. Trainer/Mentor yang telah berpengalaman akan memandu pengajaran, sehingga tercapai suasana yang interaktif dua arah.

b) Pendekatan yang digunakan dalam pelatihan ini adalah pendekatan "holistic", artinya pelatihan ini merupakan upaya untuk mengembangkan kompetensi pelayanan dan pembinaan secara utuh dan selaras dengan kompetensi pribadi dan kompetensi pengembangan bisnis.

\section{Hasil Focus Group Discussion}

Berdasarkan kesepakatan antara Tim LPPM Universitas Andalas untuk Program Pengabdian Kepada Masyarakat Membantu Nagari Membangun di Nagari Sungai Kamuyang Kecamatan Luak Kabupaten Lima Puluh Kota sebelum pelaksanaan FGD ini, fokus kegiatan yang akan dilakukan adalah Badan Usaha Milik Nagari (BUMNag) Sungai Kamuyang.
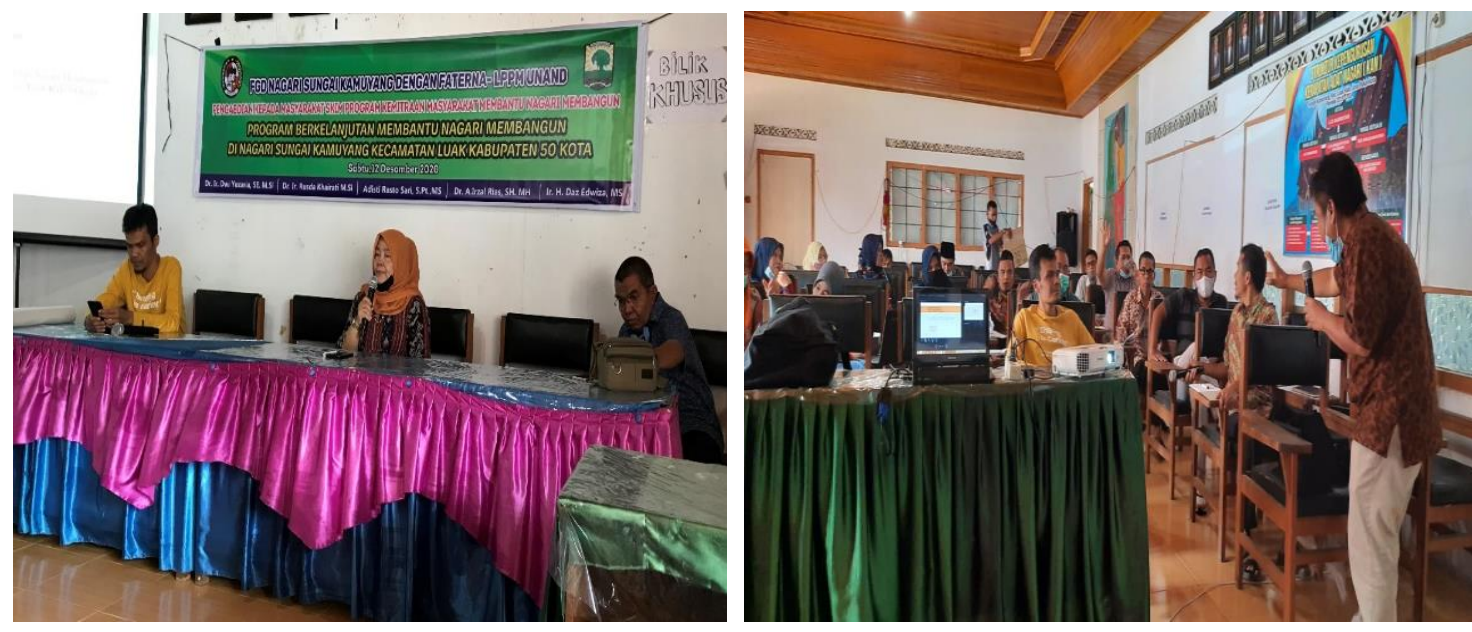

Gambar 3. Pelaksanaan FGD BUMNag Sungai Kamuyang 
Identifikasi permasalahan, solusi dan rencana kegiatan yang akan dilaksanakan yang dibahas dalam FGD ini seluruhnya berhubungan dengan BUMNag Sungai Kamuyang yang saat ini berjalan tidak lancar. Identifikasi Permasalahan BUMNag Sungai Kamuyang yang disampaikan dan dibahas bersama para peserta FGD dirinci sebagai berikut:

a. Kejelasan status BUMNag, kendatipun pendirian badan hukumnya berdasarkan Peraturan Nagari, namun masih banyak kelemahan dari Peraturan Nagari tersebut yang belum bisa memperkuat BUMNag ini sebagai badan hukum yang sah secara legal.

b. Standar laporan keuangan BUMNag Sungai Kamuyang belum mengacu kepada kaidahkaidah akuntansi yang lazim sebagai badan usaha, seperti laporan rugi laba, laporan cash in dan cash out, laporan cash flow (arus kas), laporan perubahan ekuitas, dan neraca

c. Penggunaan dana oleh pelaksana operasional (direktur, sekretaris dan bendahara) BUMNag tidak jelas dan tidak dapat dipertanggung-jawabkan yang berakibat tingginya biaya dibandingkan dengan penerimaan usaha

d. Standar akuntansi tidak dijalankan dalam penyusunan laporan keuangan, sehingga stakeholder tidak bisa mengambil keputusan atas laporan pertanggung-jawaban pelaksana operasional BUMNag

e. Rekrutmen tim manajemen/pelaksana operasional tidak melalui seleksi yang baku dan cenderung ditunjuk langsung karena hubungan kekerabatan dan hubungan lainnya, yang berakibat BUMNNag ini tidak berjalan sebagaimana layaknya badan usaha

f. BUMNag tidak memiliki rencana bisnis (business plan) dalam menjalankan bisnisnya, pelaksana operasional dan stakeholder tidak mengetahui apakah bisnis yang ditekuni layak atau tidak untuk dijalankan

g. Badan Pengawas BUMNag tidak bisa memahami laporan keuangan yang disampaikan pelaksana operasional, karena laporan keuangan disusun tidak mengikuti kaidah yang baku

h. Sistem Informasi Akuntansi (SIA) Bumdes untuk menyusun laporan keuangan yang diterbitkan BPKP tidak digunakan oleh BUMNag. Ada juga aplikasi manager produk Australia untuk laporan keuangan juga tidak digunakan

i. Sinergi pemerintahan nagari, Bamus dan BUMNag tidak ada, sehingga BUMNag tidak berjalan optimal

j. Batas kewenangan antara pelaksana operasional dan unit tidak jelas

k. Pemegang saham terbesar BUMNag adalah pemerintahan nagari, sehingga menyulitkan BUMNag berkembang, karena tidak bisa mencari mitra bisnis yang memiliki kemampuan lebih besar dari BUMNag

l. Seluruh potensi ekonomi di nagari akan dikelola BUMNag. Sementara BUMNag sendiri belum mampu mengelola bisnis-bisnis yang saat ini dikelola, hal ini dapat berakibat buruk kepada bisnis yang sudah ada, bahkan untuk bisnis yang selama ini sudah berjalan baik malah menjadi hancur

m. Badan pengawas tidak memiliki kompetensi bidang kelayakan usaha dan akuntansi, tidak bisa mengawasi usaha berjalan dengan baik atau tidak

n. Pelaksana operasional tidak memiliki jiwa entrepreneur, tidak mampu mengelola bisnis dengan baik, bahkan cenderung bekerja sendiri dan tidak mengerti akan tugas dan tanggung jawabnya sebagai pemimpin badan usaha

o. Laporan keuangan dibuat tidak sesuai dengan kaidah-kaidah akuntansi yang benar, sehingga stakeholder tidak bisa memahami makna Laporan Keuangan tersebut

p. Pemerintahan nagari tidak memiliki staf atau tenaga ahli di bidang bisnis dan akuntansi, sehingga tidak bisa memahami apakah Laporan Keuangan sudah benar atau tidak

q. Tim Audit belum bisa mengambil keputusan atas Laporan Keuangan, karena tugas pokok dan fungsi belum ada 
r. Masalah internal kepengurusan BUMNag belum terselesaikan, kepengurusan lama sudah diberhentikan dan saat ini diambil alih oleh Plt Wali Nagari

s. Badan Permusyawaratan Nagari (Bamus) tidak menerima laporan pertanggung jawaban pengurus operasional BUMNag sejak BUMNag didirikan

\section{Solusi yang Ditawarkan untuk Pengembangan BUMNag Sungai Kamuyang}

Berdasarkan permasalahan-permasalahan yang diidentifikasi dalam Focus Group Discussion (FGD), maka solusi yang ditawarkan adalah dengan melakukan kegiatan peningkatan kapasitas bisnis BUMNag yang didahului dengan pemetaan permasalahan manajemen secara menyeluruh, gap analysis, pelatihan dan dilanjutkan dengan kegiatan pendampingan dan konsultansi bisnis (business mentoring and consulting) hingga BUMNag menjadi badan usaha nagari yang mampu memberikan kontribusi kepada pemerintahan nagari.

Rincian solusi yang ditawarkan tersebut adalah sebagai berikut:

a. Peningkatan kapasitas BUMNag Sungai Kamuyang secara menyeluruh, baik dari aspek produksi, manajemen, marketing, finansial, hingga corporate culture

b. Training dan mentoring BUMNag Sungai Kamuyang

c. Mengidentifikasi unit-unit bisnis yang potensial dan strategis serta dapat diimplementasikan

d. Menyusun business plan unit-unit bisnis potensial dan strategis

Rincian solusi yang disepakati dalam FGD adalah sebagai berikut:

\section{Tahun pertama:}

a. Rekrutmen pelaksana operasional (direktur, sekretaris dan bendahara) dan badan pengawas segera dilaksanakan dengan mempertimbangkan kompetensi calon-calon yang akan seleksi, jika perlu dilakukan uji kompetensi.

b. Review unit-unit usaha yang betul potensial untuk dikembangkan dan jika ada unit bisnis startegis akan dijadikan skala prioritas

c. Riview dan atau melakukan penguatan atas aspek legal BUMNag agar status hukum badan usaha lebih kuat dan memungkinkan BUMNag dapat bermitra secara strategis

d. Review Anggaran Dasar dan Anggaran Rumah Tangga BUMNag yang memperkuat posisi BUMNag untuk menjalankan bisnisnya

e. Training and mentoring manajemen bisnis:

1) Kewirausahaan

2) Penyusunan Business Plan

3) Strategi Pemasaran

4) Manajemen Keuangan

f. Penyusunan Business Plan BUMNag Sungai Kamuyang

\section{Tahun kedua:}

a. Training and mentoring penyusunan Standard operating procedures (SOP)

b. Pengembangan networking dan partnership bisnis

c. Pengembangan market place, masuk ke e-commerce

d. Menyusun Laporan Keuangan sesuai akidah akuntansi

e. Menyusun KPI's (Key Performance Indicator's) Tim Manajemen BUMNag

\section{Tahun ketiga:}

a. Pengembangan produk-produk unggulan lokal

b. Penyusunan Laporan Keuangan (Audited)

c. e-Reporting 


\section{Target Luaran}

Jenis output yang akan dihasilkan dari masing-masing solusi pengembangan BUMNag Sungai Kamuyang tersebut adalah sebagai berikut:

a. Kinerja BUMNag Sungai Kamuyang yang semakin berkembang dan menuju ke BUMNag yang mandiri.

b. BUMNag Sungai Kamuyang memiliki badan hukum yang kuat.

c. BUMNag Sungai Kamuyang menjalankan bisnisnya mengikuti kaidah-kaidah bisnis yang profesional.

d. BUMNag Sungai Kamuyang memiliki Business Plan dalam menjalankan bisnisnya.

e. BUMNag Sungai Kamuyang memiliki dokumen SOP, manajemen mutu, Laporan Keuangan, dan dokumen pendukung bisnis lainnya.

Setiap solusi mempunyai output tersendiri dan sedapat mungkin terukur atau dapat dikuantitatifkan:

a. Produksi meningkat $10 \%$ per tahun

b. Penerimaan meningkat $15 \%$ per tahun

c. Laporan keuangan dapat dipertanggung-jawabkan (audited)

\section{Alur Pelatihan dirancang dengan memadukan ketiga unsur pengembangan SDM seperti tercermin dalam bagan berikut ini:}

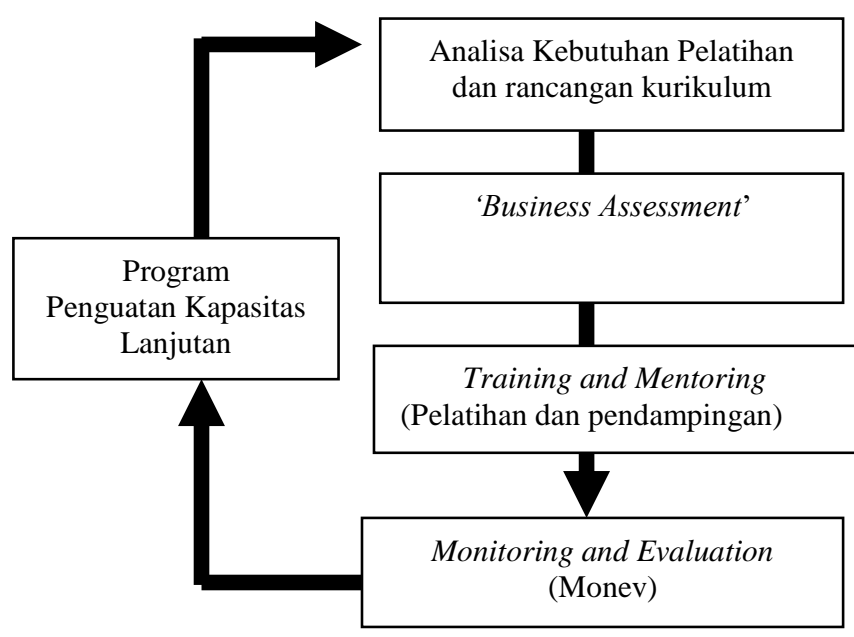

Sebelum pelatihan akan dilakukan penelitian guna melihat kebutuhan akan kurikulum yang sesuai.

Calon peserta akan melalui assessment guna melihat kesiapan mereka.

Pelatihan dan pendampingan dilakukan untuk meningkatkan kemampuan Tim Manajemen mengelola BUMNag.

Hasil training and mentoring di'review' perkembangannya dan dievaluasi capaiannya dengan menggunakan KPI's

Gambar 4. Alur Pelatihan dan Pendampingan Penguatan Kapasitas Bisnis

\section{Metode Evaluasi Pelaksanaan Kegiatan dan Keberlanjutan Program}

Tim akan menyiapkan sistem monitoring and evaluation (Monev) kegiatan peningkatan kapasitas bisnis BUMNag dengan standard internasional, yang akan disusun paralel dengan penyusunan rencana program 3 tahun. Capaian yang diharapkan pada tahun 2021-2023 sebagaimana yang ditargetkan akan dijadikan lesson learn bagi pengembangan BUMNag Sungai Kamuyang yang mandiri. Seluruh capaian tersebut disusun dalam sebuah laporan yang dapat dipertanggung-jawabkan dan dapat dilaksanakan secara bertahap selama program disepakati. Kemampuan nagari membangun daerahnya sangat tergantung kepada besarnya pendapatan asli nagari. BUMNag sebagai badan usaha milik nagari diharapkan dapat memberikan konstribusi pendapatan asli nagari, sehingga nagari bisa membiayai sendiri pembangunan daerahnya. Untuk mendukung agar nagari dapat menjadi nagari mandiri, maka BUMNag harus kuat dan mampu menghasilkan profit yang signifikan dari unit-unit usaha yang dimiliki sehingga dapat memberi kontribusi yang signifikan juga terhadap pendapatan asli nagari. Pemerintah kabupaten dan 
pemerintahan nagari diharapkan menyediakan dana pendamping/modal kerja sebagai stimulus pengembangan bisnis BUMNag Sungai Kamuyang. Pihak ketiga juga ditawarkan sebagai mitra pengembangan bisnis BUMNag untuk membiayai unit-unit usaha potensial dan strategis di tingkat nagari dan atau bahkan sampai ke tingkat kabupaten.

\section{KESIMPULAN}

Program Pengabdian kepada Masyarakat Membantu Nagari Membangun di Nagari Sungai Kamuyang Kecamatan Luak Kabupaten Lima Puluh Kota ini dilaksanakan untuk membantu nagari Sungai Kamuyang menyelesaikan masalah-masalah yang menghambat pembangunan Nagari. Permasalahan utama yang dihadapi adalah BUMNag yang mati suri dengan segala permasalahannya. Program membantu nagari membangun direncanakan akan berjalan 3 tahun dimulai dengan pemetaan permasalahan manajemen secara menyeluruh terhadap BUMNag Sungai Kamuyang, mengidentifikasi unit-unit bisnis yang potensial dan strategis serta dapat diimplementasikan, menyusun rencana bisnis terhadap unit-unit bisnis potensial dan strategis tersebut dan melakukan training dan mentoring (pelatihan dan pendampingan) bisnis bagi Tim Manajemen BUMNag Sungai Kamuyang dalam rangka penguatan kapasitas.

\section{UCAPAN TERIMA KASIH}

Kegiatan pengabdian ini didanai dengan DIPA Universitas Andalas tahun anggaran 2020 dengan nomor kontrak Kontrak No. T/53/UN.16.17/PT.PKM-MNM/LPPM/2020. Terimakasih diucapkan kepada ketua Lembaga Penelitian dan Pengabdian kepada Masyarakat Universitas Andalas, Camat Kecamatan Luak, Wali Nagari Sungai Kamuyang, Sekretaris Nagari Sungai Kamuyang, kepala-kepala jorong se nagari Sungai Kamuyang, perangkat nagari, Badan Musyawarah, kepala unit bisnis BUMNag Sungai Kamuyang dan mahasiswa yang telah membantu kelancaran kegiatan.

\section{DAFTAR PUSTAKA}

African Capacity Building Foundation (ACBF), Capacity Needs Assessment: A Conceptual Framework, dalam ACBF Newsletter, Vol. 2, 2001. Hal. 9-12.

Asrori. (2014). Kapasitas Perangkat Desa Dalam Penyelenggaraan Pemerintahan Desa di Kabupaten Kudus. Jurnal Bina Praja, 6 (2), 101-116.

Febriana NLM dan Made S. 2015. Pengaruh kepemimpinan transformasional, budaya organisasi dan Kompensasi Finansial pada kinerja karyawan. Jurnal Manajemen UNUD Vol 4 No 5.

Hasibuan, Malayu S.P., Drs., 2007. Manajemen Sumber Daya Manusia.edisi revisi, Jakarta: PT. Bumi Aksara.

Kuryanto, K., dan M. Syarifuddin. 2008. Pengaruh Modal Intelektual Terhadap Kinerja Perusahaan. Simposium Nasional Akuntansi XI, Pontianak. 
Leba, E. G. (2015). Kapasitas Desa dalam Pelaksanaan Otonomi Desa. Onilne: Http://Www.Academia.Edu/6688453/ Kapasitas Desa Dalam Pelaksanaan Otonomi Desa diunduh 26 November 2020.

Milen, Anelli, (2004). Pegangan Dasar Pengembangan Kapasitas (Diterjemahkan secara bebas). Yogyakarta: Pondok Pustaka Jogja.

Punch, K.F. (2014). Introduction to Sosial Research: Quantitative and Qualitative Approaches (Edisi ke-3). London: Sage Publication. 